\title{
Resenha: Comunicar(se) en el siglo XXI: Doce propuestas de estudio sobre la comunicación
}

\author{
Heloísa Pezza Cintrão*
}

García González, M.; García González, A. (eds.) Comunicar(se) en el siglo xxi: Doce propuestas de estudio sobre la comunicación. Granada: Comares, 2014. 245 p.

O livro Comunicar(se) en el siglo xxi, publicado em 2014 pela Editora Comares de Granada, Espanha, reúne 12 estudos e um texto de apresentação, todos de autores vinculados ao Programa de Doutorado em Comunicação da Universidade de Vigo, na Comunidade Autônoma da Galícia, Espanha. Trata-se de um Programa de Pós-Graduação interdisciplinar, que começou a funcionar também no ano de 2014, cuja interface com os Estudos da Tradução é explicitada em cinco de suas sete linhas de pesquisa: (1) Teoria e história da comunicação; (2) Comunicação virtual, ciberjornalismo e tecnologias da tradução; (3) Comunicação organizacional e relações públicas; (4) Sociologias da tradução e da comunicação; (5) Tradução e comunicação especializadas; (6) Literatura, linguística e tradução; (7) Tradução multimídia.

Os capítulos do livro apresentam-se emoldurados por duas reflexões acerca das convergências entre Estudos da Tradução e da Comunicação, feitas na apresentação e no último capítulo.

Em "Comunicar(se) en el siglo xxi: ¿Qué ha cambiado? ¿Qué sigue igual?", as organizadoras do volume, Marta García González e Aurora García

\footnotetext{
"Professora pesquisadora do Programa de Pós-Graduação em Estudos da Tradução e do Programa de Pós-Graduação em Língua Espanhola e Literaturas Espanhola e HispanoAmericana da Universidade de São Paulo.
} 
CINTRÃo, H. P. - Resenha: Comunicar(se) en el siglo XXI: Doce propuesta de estúdio sobre la comunication

González, discutem a complexidade de delimitar as comunicações como objeto de certo campo disiplinar e ilustram essa complexidade com a diversidade de setores da disciplina geral das Comunicações enumerados pela National Communication Association (NCA) dos Estados Unidos, vários deles mencionando a tradução e a comunicação intercultural. Ressalta-se que a mediação é um elemento imprescindível em numerosas situações comunicativas e que, tendo como definição 'expressar numa língua aquilo que se encontrava escrito ou expresso antes em outra', traduzir é comunicar. Por outro lado, também comunicar é traduzir "por meio da palavra, de gestos, de expressões, de imagens, de ícones, etc. um pensamento, um interesse ou uma ideia para que outro possa ser partícipe deles". Esse estreito contato entre Comunicações e Estudos da Tradução subjaz à organização tanto do livro quanto do doutorado da UVigo e dá unidade aos diferentes capítulos do volume. Por fim, a apresentação discute em que medida as comunicações e a tradução se viram reconfiguradas no século XXI com a globalização dos mercados e com o desenvolvimento das tecnologias da informação.

O tema das convergências e coincidências entre Estudos da Tradução e das Comunicações é retomado e esmiuçado por Oscar Diaz Fouces no capítulo final do volume, "Algunas reflexiones sobre la ubicación académica de los Estudios de Traducción", numa discussão crítica que percorre ampla e criteriosa bibliografia a respeito da configuração dos campos do conhecimento, sempre com vistas a inquirir a localização das Comunicações e especialmente dos Estudos da Tradução nesse mapeamento. Aponta-se esses dois campos como intrinsecamente interdisciplinares e a superposição clara entre seus objetos de estudo, além de diversos pontos de contato entre eles, como o tipo de organização acadêmica e a forma de divulgação predominante de seus resultados de pesquisa.

Emoldurados pelas reflexões anteriores, os demais capítulos são estudos diversificados. Entre os diretamente vinculados aos Estudos da Tradução está o capítulo de Jesús Meiriño-Gómez, "Specialised 
CINTRÃo, H. P. - Resenha: Comunicar(se) en el siglo XXI: Doce propuesta de estúdio sobre la comunication

Communication in English and Spanish: a Corpus-Based Study on Paul Krugman's Press Articles", que examina a tradução de metáforas no campo da economia, a partir de um corpus paralelo bilíngue unidirecional composto de artigos de Paul Krugman publicados em inglés no The New York Times e de suas traduções para o castelhano, publicadas no jornal espanhol El País.

Dois dos capítulos tratam de casos de tradução audiovisual e acessibilidade, temas que têm merecido bastante atenção dos Estudos da Tradução na atualidade. No capítulo "Analysis of Technical and Stylistic Aspects of Creative Subtitling and their Application to Audiovisual. Products for Deaf and hard of hearing Children: Towards an Improvement in Communicative Success", Cayetana Álvarez Raposeiras se vale de exemplos em produtos audiovisuais para propor uma classificação de aspectos técnicos e estilísticos de um tipo de legendagem que foge aos padrões tradicionais, voltada para um público infantil de surdos e deficientes auditivos: a legendagem criativa. "Comunicación, accesibilidad, nuevas tecnologías y ocio: el 'teatro accesible' (en minúsculas y en mayúsculas)", de Joan Miquel-Vergés, trata da acessibilidade no teatro, incrementada por tecnologias atuais que permitem que pessoas com deficiências visuais ou auditivas assistam regularmente espetáculos teatrais, descrevendo o caso da iniciativa Teatro Acessivel, concebida numa colaboração entre associações e empresas.

Outros capítulos focalizam diferentes mídias e cenários da comunicação no século XXI, em relação com novas condições decorrentes da globalização e/ou das inovações tecnológicas.

"La fotografía y el lenguaje como fuente de la memoria histórica social", de Joaquín Antonio Vallejo Moreno, aborda a imagem fotográfica como via de acesso à história e à memória coletiva, propondo caminhos de compreensão da fotografia no contexto histórico e social, a partir do exame de dois casos, uma fotografia de arquivos históricos do Peru e outra do México, cujo estudo envolveu a tradução para o castelhano de testemunhos recolhidos em línguas indígenas. 
CINTRÃo, H. P. - Resenha: Comunicar(se) en el siglo XXI: Doce propuesta de estúdio sobre la comunication

A comunicação na imprensa escrita entra em foco nos capítulos "Medios alternativos como respuesta al proceso de homogeinización informativa: la prensa gallega" e "El humor gráfico en la prensa: de la opinión desiludida a la opinión desubicada". No primeiro, Lorena Arévalo Iglesias y Alba López Bolás examinam diferenças de conteúdos e de tratamento desses conteúdos em jornais da mídia tradicional e em veículos alternativos da Comunidade Autônoma da Galícia. Entre os objetivos do estudo está o de considerar a presença na web de uma mídia alternativa surgida nos últimos 6 anos (imprensa digital) como contrapeso à tendência jornalística crescente de usar informações procedentes de grandes agências de notícias, esta última com impactos negativos como a desvinculação dos temas considerados noticiáveis de acontecimentos de interesse local. A conclusão é que a mídia alternativa analisada de fato vem desempenhando um papel relevante para contrabalançar a homogeinização da informação. No segundo estudo relacionado à imprensa escrita, o questionamento de Félix Caballero Wangüemert e Mercedes Román Portas é se as seções dos jornais em que o humor gráfico costuma ser publicado são de fato adequadas ou se esse gênero jornalístico deveria situar-se nas páginas de opinião. Os autores mostram que o humor gráfico tem uma evidente vocação especulativa e crítica que o assemelha aos gêneros jornalísticos de opinião, mas o caráter sui generis, difuso, da opinião no humor gráfico leva a seu frequente deslocamento para páginas de entretenimento ou amenidades.

Dois capítulos focalizam a comunicação audiovisual, um deles na telinha e outro no telão. Em "Children's Programming on Spanish Regional Channels: The Case of the Galician Television (TVG)", Beatriz Feijoo Fernández e Aurora García González examinam o caso do programa infantil Xabarín Club, da televisão pública galega, e como sua transferência da TVG para um canal público mais secundário, em combinação com a diversificação da oferta de programação infantil num canal privado, parecem ter provocado uma perda do impacto social que o programa havia tido nos anos noventa. Em 
CINTRÃo, H. P. - Resenha: Comunicar(se) en el siglo XXI: Doce propuesta de estúdio sobre la comunication

"Señas de identidad de la marca James Bond", Vicente Badenes Pla se vale do conceito de "marca" para procurar discernir o conjunto de traços de identidade que fizeram da série do 007 um sucesso de bilheteria no mundo todo, junto a um público global de todas as condições sociodemográficas e com longevidade ímpar dentre as séries cinematográficas (50 anos).

No campo da comunicação não verbal, o capítulo "O 'Social Training' como instrumento para reforçar e aumentar o entendimento da comunicação não verbal e da sua importância para o processo de tomada de decisões e escolhas", de Maria João Ramos Monteiro Soares Ribeiro defende que, na situação comunicativa, a linguagem corporal tem um poder de persuasão que chega a superar o das palavras, ainda que inconscientemente, e apresenta uma proposta de formação para melhorar o domínio dos elementos não verbais em interações comunicativas.

No capítulo "Estrategias publicitarias innovadoras en la economía del conocimiento: el papel del espíritu emprendedor corporativo", de $M^{a}$ Esmeralda Lardón López e Víctor J. García Morales, os autores partem de um conjunto de dados de diversas fontes para levantar, com foco em empresas de comunicação e publicidade, a seguinte questão: o espírito empreendedor corporativo, vinculado ao capital intelectual existente na empresa, seria um fator capaz de responder à necessidade de inovação permanente no novo paradigma da "sociedade do conhecimento", a despeito da diminuição de investimentos em ativos materiais tecnológicos? Em situações de carência de recursos para investir em melhorias tecnológicas, como é o cenário da atual crise econômica mundial, o estudo do desempenho inovador vinculado ao capital imaterial deveria ser aprofundado, sustentam os autores.

"El Derecho en tanto cultura, la cultura del Derecho: nuevos campos de comunicación y mediación en ámbitos histórico sistémicos altamente diferenciados", de Arturo Parada Diéguez, trata da evolução do Direito como disciplina estreitamente vinculada à comunicação e à mediação, e examina como as mudanças mais recentes no campo do Direito, em relação com os 
CINTRÃo, H. P. - Resenha: Comunicar(se) en el siglo XXI: Doce propuesta de estúdio sobre la comunication

processos de globalização, deriva em consequências significativas para os mediadores interculturais no campo jurídico.

O conjunto dos capítulos compõe uma representação geral do Programa de Doutorado em Comunicações da Universidade de Vigo, das temáticas contempladas em suas linhas de pesquisa e da forma como a inserção dos Estudos da Tradução foi pensada nesse Programa, em diálogo estreito, por um lado, com as Comunicações e, por outro, com as questões mais atuais da globalização e das tecnologias do século XXI. 